\section{Einladung zur Mitgliederversammlung der DRG am Donnerstag, den 5. Mai 2016}

Zur ordentlichen Mitgliederversammlung der Deutschen Röntgengesellschaft - Gesellschaft für Medizinische Radiologie e.V. (DRG), am Donnerstag, den 5. Mai 2016, von 17:30-19:00 Uhr im Congress Centrum Leipzig (CCL), lädt der Vorstand der DRG die Mitglieder der DRG hiermit herzlich ein. (Raum wird noch bekannt gegeben).

\section{Tagesordnung}

TOP 1 Begrüßung

TOP 2 Totengedenken

TOP 3 Genehmigung des Protokolls der Mitgliederversammlung vom 14. Mai 2015 (veröffentlicht im Jahresbericht 64, Januar 2016)

TOP 4 Bericht des Präsidenten

TOP 5 Bericht des Schatzmeisters

TOP 6 Bericht der Kassenprüfer

TOP 7 Entlastung des Vorstands

TOP 8 Vorschläge für Ehrungen 2017

TOP 9 Wahl der Kassenprüfer 2017

TOP 10 Wahl des Kongresspräsidenten 2019

TOP 11 Bericht der Akademie für Fortund Weiterbildung in der Radiologie

TOP 12 Bericht des Vorsitzenden der Vereinigung Medizinisch-Technischer Berufe in der DRG (VMTB)

TOP 13 Bericht des Justitiars der DRG
TOP 14 Einladung zum Röntgenkongress 2017

TOP 15 Ausgliederung des Teilbereichs steuerpflichtige wirtschaftliche Geschäftsbetriebe Fremdveranstaltungen, Zertifizierungen und Geschäftsbesorgung für Fachgesellschaften (,Teilbetrieb') aus der DRG - Gesellschaft für Medizinische
Radiologie e.V. mit Sitz in Berlin (,DRG e. V. ) durch die DRG Service GmbH

TOP 16 Verschiedenes

Die Einlasskontrolle erfolgt über den Kongressausweis. Entsprechend der Satzung der DRG können an der Mitgliederversammlung nur Mitglieder teilnehmen, deren Beitragskonto für 2016 ausgeglichen ist.

Im Namen des Vorstandes Prof. Dr. Dierk Vorwerk (Präsident) 